\title{
Limited efficacy of propranolol on the reconsolidation of fear memories
}

\author{
Elizaveta V. Muravieva ${ }^{1}$ and Cristina M. Alberini ${ }^{1,2,3}$ \\ ${ }^{1}$ Department of Neuroscience, Mount Sinai School of Medicine, New York, New York 10029, USA; ${ }^{2}$ Department of Psychiatry, \\ Mount Sinai School of Medicine, New York, New York 10029, USA
}

\begin{abstract}
Previous studies suggested that the $\beta$-adrenergic receptor antagonist propranolol might be a novel, potential treatment for post-traumatic stress disorder (PTSD). This hypothesis stemmed mainly from rodent studies showing that propranolol interferes with the reconsolidation of Pavlovian fear conditioning (FC). However, subsequent investigations in humans have produced controversial evidence about the effect of propranolol on fear memories and an effect on PTSD symptomatology has yet to be reported. Thus, it remains to be established whether propranolol interferes with the reconsolidation of fear memories at large. To address this question, we tested the effect of systemic injections of propranolol administered before or after the retrieval of an inhibitory avoidance (IA) memory elicited with different footshock intensities. In parallel, the same treatment was tested on the reconsolidation of Pavlovian FC. Propranolol showed no effect on the reconsolidation of IA, although the pre-retrieval administration resulted in a significant retrieval impairment. This impairment was transient, and memory returned to control levels at later times. In agreement with previous studies, we found that systemic administration of propranolol disrupts the reconsolidation of Pavlovian FC and that its injection following a retrieval elicited by cue exposure also interferes with the reconsolidation of contextual FC. Hence, propranolol disrupts the reconsolidation of Pavlovian FC, but has no effect on the reconsolidation of IA. The results indicate that the efficacy of systemic administration of propranol in disrupting the reconsolidation of fear memories is limited.
\end{abstract}

A new memory exists for a limited time in a labile state and becomes a long-lasting memory through a process of stabilization known as consolidation (McGaugh 2000). During the labile phase of consolidation, memory can be disrupted by several treatments including inhibition of protein and RNA synthesis and blockade of a number of neurotransmitter and hormone receptors as well as of downstream molecular pathways (Davis and Squire 1984; Izquierdo and Medina 1997; Kandel 2001). Over time, memories become resistant to disruption by these treatments, but they can again become transiently sensitive if they are reactivated, for example, by retrievals of the memory (Nader et al. 2000; Alberini 2005). The reactivated memory, like the new memory during the post-training consolidation phase, again undergoes a stabilization process known as reconsolidation (Nader et al. 2000; Sara 2000). Several types of memories in many different species undergo reconsolidation following their reactivation (Alberini et al. 2006). Interfering with the reconsolidation process provides an opportunity for disrupting memories that may contribute to the development of psychiatric disorders such as post-traumatic stress disorder (PTSD) or addiction (Dudai 2006; Diergaarde et al. 2008; Taylor et al. 2009). Recently, several pharmacological compounds have been tested in animal models of fear learning in order to identify drugs that can be potentially relevant for clinical trials of trauma-induced pathologies and, in particular, PTSD (Debiec and LeDoux 2006; Brunet et al. 2008; Taubenfeld et al. 2008). Particular attention has been given to blockers of stress hormones, including antagonists of glucocorticoid or $\beta$-adrenergic receptors.

We previously reported that the glucocorticoid receptor antagonist RU38486 persistently disrupts inhibitory avoidance

\footnotetext{
${ }^{3}$ Corresponding author.
}

E-mail cristina.alberini@mssm.edu; fax (212) 996-9785.

Article is online at http://www.learnmem.org/cgi/doi/10.1101//m.1794710.
(IA) memory retention if administered either in the amygdala or systemically immediately following retrieval (Tronel and Alberini 2007; Taubenfeld et al. 2008). Thus, we were interested in investigating the potential synergistic effect of blocking both glucocorticoid and $\beta$-adrenergic receptors. Several studies from other laboratories have investigated the effect of the $\beta$-adrenergic receptor antagonist propranolol on fear memories, but reported conflicting conclusions. Propranolol administered in combination with memory retrieval disrupts auditory fear conditioning (FC) (Debiec and LeDoux 2004) and has a modest, although significant disruptive effect on contextual FC (Abrari et al. 2007). Furthermore, propranolol has been reported to disrupt Pavlovian reward conditioning (Diergaarde et al. 2006). Following these animal-based investigations, some clinical and human studies have shown that pre- or post-retrieval propranolol administration reduces psycho-physiological responses to mental imagery of a past traumatic event in PTSD patients (Brunet et al. 2008) and disrupts potentiation of the eyeblink startle reflex, but not the acquired contingency between the conditioned (CS) and unconditioned stimulus (US) in healthy human subjects (Kindt et al. 2009). Thus, propranolol administered in combination with memory retrieval has been proposed to eliminate fear responses without affecting declarative memory (Kindt et al. 2009). Other studies found no change of pre-retrieval propranolol administration on both physiological responses to traumatic memory (Tollenaar et al. 2009) and verbal emotional memories (Tollenaar et al. 2008) in healthy human subjects. Furthermore, an effect of propranolol on PTSD symptomatology has not yet been reported. Hence, it is still unclear whether systemic treatment of propranolol has a general effect on the reconsolidation of fear-based memories or whether it affects only some types of fear memory responses.

Here, we tested whether the reconsolidation of the instrumental fear-conditioning IA, which is disrupted by protein synthesis inhibitors as well as antagonists of glucocorticoid 
receptors (Milekic and Alberini 2002; Taubenfeld et al. 2008), can be affected by systemic administrations of propranolol.

\section{Results}

\section{Propranolol administrated systemically immediately after retrieval has no effect on IA memory regardless of the footshock intensity used during training}

In the first set of experiments, we investigated the effect of systemic administration of propranolol on IA memory reconsolidation. Toward this end, we used the same behavioral protocol that previously showed that IA reconsolidation is disrupted by post-retrieval administration of the protein synthesis inhibitors anisomycin and cycloheximide (Milekic and Alberini 2002; Milekic et al. 2007) as well as of the antagonist of glucocorticoid receptors RU38486 (Taubenfeld et al. 2008). Groups of rats were trained with $0.9 \mathrm{~mA}$ footshock intensity and tested $48 \mathrm{~h}$ later (Test 1). This test served to both measure IA memory and reactivate it. Immediately after, the rats were injected intraperitoneally (i.p.) with either $10 \mathrm{mg} / \mathrm{kg}$ of propranolol or saline and tested again $48 \mathrm{~h}$ later (Test 2 ). This dosage of propranolol is one of the highest previously used in several studies to interfere with the consolidation or reconsolidation in several different types of memories, including both aversive and appetitive (e.g., Sara et al. 1995; Przybyslawski et al. 1999; Saber and Cain 2003; Debiec and LeDoux 2004; Diergaarde et al. 2006; Abrari et al. 2007; Milton et al. 2008; Rodriguez-Romaguera et al. 2009). All groups of rats had similar retention latencies at Test 1 and Test 2. A two-way analysis of variance (ANOVA) comparing avoidance scores across treatment and tests (Test 1 -Test 2 ) revealed no effect of treatment $\left(F_{(1,24)}=0.006, P=0.94\right)$, no effect of test $\left(F_{(1,24)}=0.15, \quad P=0.7\right)$, and no test $\times$ treatment interaction $\left(F_{(1,24)}=1.94, P=0.18\right)$. Bonferroni post-hoc test showed no significant differences between propranolol and saline at both Test $1(P>0.05)$ and Test $2(P>0.05$; Fig. 1A; Table 1$)$.

Because previous studies by Przybyslawski et al. (1999) have reported that propranolol disrupts an IA memory evoked by very low shock intensities ( $0.25 \mathrm{~mA}$ footshock), we set out to determine whether the effect of propranolol is restricted to IA memories evoked by low footshock intensities. Thus, we used the same protocol used for the $0.9 \mathrm{~mA}$ described above to test the effect of propranolol on IA elicited by either 0.6 or $0.25 \mathrm{~mA}$ footshock. As depicted in Figure $1 \mathrm{~B}$ and Table 1, rats trained with $0.6 \mathrm{~mA}$ had similar retention latency at Test 1 and showed
B
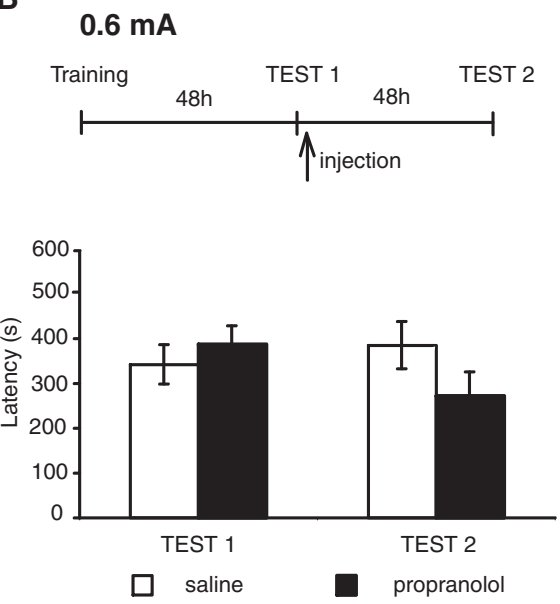

D

$0.6 \mathrm{~mA}$
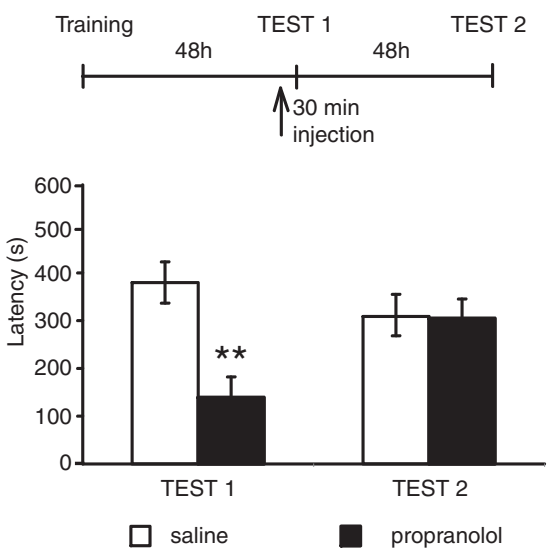

Figure 1. Propranolol administered systemically impairs IA retrieval but has no effect on reconsolidation. Experimental timelines are shown above each experiment. Values of latencies are expressed in and shown as means \pm SEM. $(A)$ Animals were trained in IA with $0.9 \mathrm{~mA}$ footshock intensity (Test 1), and immediately after, they were injected i.p. with propranolol or groups. (B) Animals underwent the same experimental protocol as in $A$, except that $0.6 \mathrm{~mA}$ footshock intensity was used during training. No significant effect of treatment was found among groups. (C) Animals underwent the same experimental protocol as in $A$, except that $0.25 \mathrm{~mA}$ footshock intensity underwent the same experimental protocol as in $B$, except that they received an i.p. injection of propranolol 30 min before reactivation (Test 1). Compared with saline, propranolol significantly disrupted IA retention at Test $1(* *, P<0.01)$, but not at Test 2 .

a tendency toward a decrease in latency after propranolol treatment compared with saline at Test 2. This tendency, however, was not statistically significant. A two-way ANOVA comparing avoidance scores across treatment and tests (Test 1-Test 2) revealed no effect of treatment $\left(F_{(1,42)}=0.48, P=0.50\right)$, no effect of test $\left(F_{(1,42)}=0.55, P=0.46\right)$, and no test $\times$ treatment interactions $\left(F_{(1,42)}=2.64, P=0.11\right)$. Figure $1 \mathrm{C}$ and Table 1 show the results obtained with $0.25 \mathrm{~mA}$ shock intensity. As described in the Materials and Methods' section, in all of our studies we used the full entry into the dark box as a measure of the avoidance (latency). At both Test 1 and Test 2, our rats showed very low and similar latencies to enter the shock compartment, which, in addition, did not significantly differ from the initial acquisition latencies (saline, $18.8 \pm 3.5 \mathrm{sec}$; propranolol, $15.9 \pm 4.2 \mathrm{sec}$ ). 
Table 1. Scores indicating the mean latency (seconds) or freezing level (percent) \pm SEM and $n$ per each experiment described in the Results section

\begin{tabular}{|c|c|c|c|c|}
\hline Experiments & Groups & & Scores & \\
\hline $\begin{array}{l}\text { Figure } 1 \\
\text { A. } 0.9 \mathrm{~mA} \text { shock IA, } \\
\text { propr after RA } \\
\text { B. } 0.6 \mathrm{~mA} \text { shock IA, } \\
\text { propr after RA } \\
\text { C. } 0.25 \mathrm{~mA} \text { shock IA, } \\
\text { propr after RA } \\
\text { D. } 0.6 \mathrm{~mA} \text { shock IA, } \\
\text { propr before RA }\end{array}$ & $\begin{aligned} \text { Sal } n & =7 \\
\text { Propr } n & =7 \\
\text { Sal } n & =10 \\
\text { Propr } n & =13 \\
\text { Sal } n & =6 \\
\text { Propr } n & =6 \\
\text { Sal } n & =8 \\
\text { Propr } n & =8\end{aligned}$ & $\begin{array}{c}\text { Test } 1 \\
409.9 \pm 46.3 \mathrm{sec} \\
476.4 \pm 33.0 \mathrm{sec} \\
342.1 \pm 44.0 \mathrm{sec} \\
387.4 \pm 40.7 \mathrm{sec} \\
16.6 \pm 5.2 \mathrm{sec} \\
27.7 \pm 13.7 \mathrm{sec} \\
379.6 \pm 43.5 \mathrm{sec} \\
139.3 \pm 43.1 \mathrm{sec}\end{array}$ & $\begin{array}{c}\text { Test } 2 \\
490.2 \pm 46.2 \mathrm{sec} \\
430.6 \pm 53.3 \mathrm{sec} \\
384.8 \pm 52.7 \mathrm{sec} \\
272.6 \pm 52.7 \mathrm{sec} \\
10.6 \pm 2.6 \mathrm{sec} \\
14.8 \pm 5.6 \mathrm{sec} \\
308.7 \pm 46.4 \mathrm{sec} \\
304.9 \pm 40.4 \mathrm{sec}\end{array}$ & \\
\hline $\begin{array}{l}\text { Figure } 2 \\
\text { A. FC cue RA }\end{array}$ & $\begin{array}{r}\text { Sal } n=8 \\
\text { Propr } n=8\end{array}$ & $\begin{array}{l}\text { Reactivation } \\
83.4 \pm 4 \% \\
76.6 \pm 4.3 \%\end{array}$ & $\begin{array}{c}\text { Cue test } \\
56.6 \pm 4.3 \% \\
17.7 \pm 3.8 \%\end{array}$ & $\begin{array}{l}\text { Context test } \\
56.6 \pm 5.5 \% \\
18.4 \pm 4.9 \%\end{array}$ \\
\hline $\begin{array}{l}\text { B. FC contextual RA } \\
\text { C. FC no RA }\end{array}$ & $\begin{array}{r}\text { Sal } n=8 \\
\text { Propr } n=8 \\
\text { Sal } n=6 \\
\text { Propr } n=6\end{array}$ & $\begin{array}{l}\text { Reactivation } \\
42.8 \pm 4.2 \% \\
49.2 \pm 4.9 \%\end{array}$ & $\begin{array}{c}\text { Context test } \\
58.4 \pm 3.6 \% \\
31.2 \pm 2.6 \% \\
\text { Cue test } \\
61.1 \pm 7.6 \% \\
67.8 \pm 3.8 \%\end{array}$ & $\begin{array}{c}\text { Cue test } \\
54.1 \pm 4.8 \% \\
49.9 \pm 4.9 \% \\
\text { Context test } \\
63.3 \pm 6.9 \% \\
65.1 \pm 7.0 \%\end{array}$ \\
\hline D. FC novel context & $\begin{array}{r}\text { Sal } n=6 \\
\text { Propr } n=6\end{array}$ & $\begin{array}{l}\text { Reactivation } \\
12.6 \pm 4.9 \% \\
13.8 \pm 5.5 \%\end{array}$ & $\begin{array}{c}\text { Cue test } \\
56.5 \pm 3.8 \% \\
62.3 \pm 3.9 \%\end{array}$ & $\begin{array}{l}\text { Context test } \\
56.0 \pm 3.9 \% \\
58.6 \pm 5.1 \%\end{array}$ \\
\hline $\begin{array}{l}\text { Figure } 3 \\
\text { A. IA + cue } \\
0.6 \mathrm{~mA} \text { shock } \\
\text { B. IA + cue } \\
0.9 \mathrm{~mA} \text { shock }\end{array}$ & $\begin{array}{r}\text { Sal } n=7 \\
\text { Propr } n=7 \\
\text { Sal } n=5 \\
\text { Propr } n=4\end{array}$ & $\begin{array}{c}\text { Test } 1 \\
372.4 \pm 49.4 \mathrm{sec} \\
304.8 \pm 29.2 \mathrm{sec} \\
439.5 \pm 45.6 \mathrm{sec} \\
388.7 \pm 30.2 \mathrm{sec}\end{array}$ & $\begin{array}{c}\text { Test } 2 \\
321.1 \pm 36.1 \mathrm{sec} \\
308.5 \pm 62.1 \mathrm{sec} \\
422.3 \pm 40.9 \mathrm{sec} \\
468.7 \pm 27.1 \mathrm{sec}\end{array}$ & $\begin{array}{r}\text { Cue test } \\
23.8 \pm 3.7 \% \\
9.8 \pm 1.2 \% \\
20.7 \pm 3.5 \% \\
5.8 \pm 1.9 \%\end{array}$ \\
\hline
\end{tabular}

propranolol impairs the retrieval of IA memory, but does not disrupt its reconsolidation.

\section{Propranolol administered systemically after retrieval disrupts both cued and contextual FC reconsolidation: Effect of retrieval modality}

Our results showing that propranolol fails to affect IA memory reconsolidation are conceptually divergent from previous studies, concluding that the same antagonist and dosage significantly and persistently disrupts Pavlovian fear memory reconsolidation. Specifically, it had been reported that propranolol injected either into the basolateral amygdala or i.p. after reactivation by a tone CS disrupts the reconsolidation of an auditory FC (Debiec and LeDoux 2004). Thus, to confirm and extend these findings, in the next set of experiments we tested the effect of propranolol on the reconsolidation of contextual and auditory FC.

In the first experiment, we tested the effect of propranolol administered following retrieval elicited by a tone (cue) presentation. Rats were trained in

Two-way ANOVA, comparing scores across treatment and tests, revealed no effect of test $\left(F_{(2,30)}=0.95, P=0.39\right.$; Fig. 1C), no effect of treatment $\left(F_{(1,30)}=0.54, P=0.47\right)$, and no treatment $\times$ test interaction $\left(F_{(2,30)}=0.52, P=0.60\right)$.

Together, these results show that the propranolol administered systemically after retrieval induced by a nonreinforced context exposure has no effect on IA memory reconsolidation.

\section{Propranolol administered systemically 30 min before retrieval affects retrieval but not reconsolidation of IA}

Previous studies have shown that the time window of sensitivity to the effect of amnesic treatments administered following retrieval is relatively short (Anokhin et al. 2002). Thus, we investigated whether propranolol injected $30 \mathrm{~min}$ before reactivation affects IA memory at subsequent tests. Reactivation, as in all of our IA experiments, consisted of exposure to the context during testing (Test 1). For these experiments, we used the $0.6 \mathrm{~mA}$ footshock intensity, because with this shock intensity we had found that propranolol resulted in a nonsignificant tendency to decrease IA memory at Test 2 (see Fig. 1B). Groups of rats were trained and injected i.p. a half-hour before reactivation (47.5 $\mathrm{h}$ after training; Test 1 ) with either propranolol or saline. This test reactivated the memory. Forty-eight hours later, the animals were tested again (Test 2). A two-way ANOVA comparing avoidance scores across treatment and tests revealed a significant effect of treatment $\left(F_{(1,28)}=7.91, P<0.01\right)$, no effect of test $\left(F_{(1,28)}=1.19, P=0.28\right)$, and significant effect of test $\times$ treatment interaction $\left(F_{(1,28)}=7.42, P<0.01\right)$. Bonferroni posthoc test showed that, compared with saline, propranolol disrupted the latencies at Test $1(P<0.01)$. However, at Test 2 , both saline- and propranolol-treated groups had similar and intact retentions $(P>0.05$; Fig. 1 D; Table 1$)$. We concluded that
FC in context A. Forty-eight hours later they were presented with the tone in a different context (tone in context B), and immediately after they received an i.p. injection of either propranolol or saline. Forty-eight hours and $96 \mathrm{~h}$ later, the animals were tested for cue and contextual freezing in contexts $\mathrm{B}$ and $\mathrm{A}$, respectively (Fig. 2A; Table 1). During the reactivation, all rats showed similar freezing levels, which were low before the cue onset (saline, $16.1 \pm 2.1 \%$; propranolol, $12.4 \pm 3.0 \%$ ) and high during the cue presentation. Two-way ANOVA comparing freezing scores across groups before and after cue exposure revealed a significant effect of the cue presentation $\left(F_{(1,26)}=335.5, P<0.0001\right)$, no effect of group $\left(F_{(1,26)}=2.03, P=0.17\right)$, and no group $\times$ cue exposure interaction $\left(F_{(1,26)}=0.17, P=0.68\right)$. Two-way ANOVA comparing freezing scores across treatment and tests (cue and context) revealed a significant effect of treatment $\left(F_{(1,26)}=74.9, P<\right.$ $0.0001)$, no effect of test $\left(F_{(1,26)}=0.01, P=0.94\right)$, and no test $\times$ treatment interactions $\left(F_{(1,26)}=0.00, P=0.95\right)$. Bonferroni posthoc comparison showed that compared with saline, propranololtreated rats froze significantly less during both the cue test $(P<$ $0.001)$ and subsequent contextual test $(P<0.001)$. Hence, propranolol administered immediately after a cue reactivation disrupts both cue and contextual memory reconsolidation.

In the second experiment, we tested the effect of propranolol administered after a contextual reactivation on both contextual and cued fear memories, respectively (Fig. 2B; Table 1). Rats trained as described above were exposed to the contextual reactivation (in the training context or context A). Immediately after, they received an i.p. injection of either propranolol or saline. Forty-eight hours later they were tested for contextual freezing (in context A) and then, $2 \mathrm{~d}$ later, for auditory freezing (in context B). Student's $t$-test comparing freezing scores between groups during contextual reactivation (RA context) revealed no significant differences $(P>0.34)$. A two-way ANOVA comparing freezing scores across treatment and test (cue and contextual tests) 
A
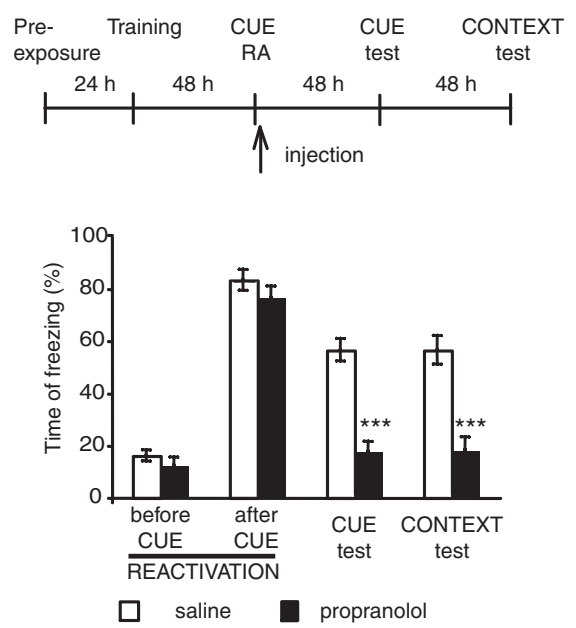

C
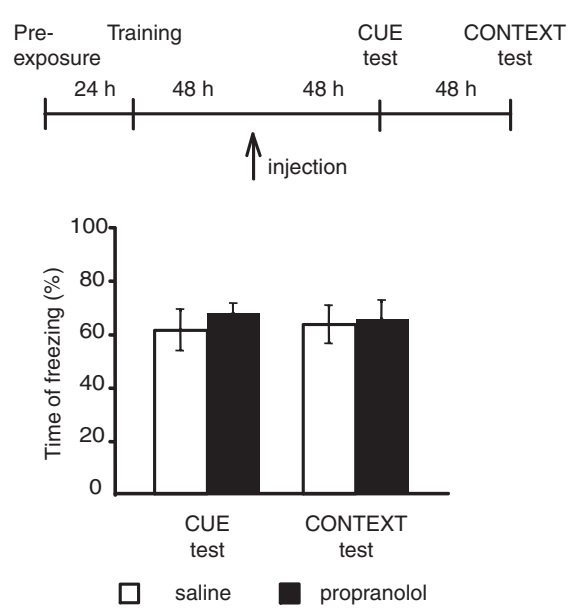

Figure 2. Propranolol administered systemically after reactivation disrupts both cue- and contextual-FC reconsolidation. Cue reactivation influences contextual memory. Experimental timelines are shown above each experiment. Freezing scores are expressed as percent of the total time of testing and shown as means \pm SEM. $(A)$ Rats were trained in FC. Forty-eight hours later, they were presented with the tone in a different context and immediately after, received an i.p. injection of either propranolol or saline. Forty-eight hours and $96 \mathrm{~h}$ later, the animals were tested for cue and contextual freezing, respectively. Propranolol significantly disrupted FC in both cue and context tests $(* * *, P<0.001)$. (B) Rats were trained in FC and exposed to the training context $48 \mathrm{~h}$ later. Immediately after context exposure, rats received an i.p. injection of either propranolol or saline. Forty-eight hours and $96 \mathrm{~h}$ later, the animals were tested for contextual and cue freezing, respectively. Propranolol significantly disrupted contextual fear memory but did not affect cued fear memory $\left.*^{* *}, P<0.001\right)$. (C) Rats were trained and received propranolol or saline injections as in $A$ in the absence of reactivation. Forty-eight hours and $96 \mathrm{~h}$ after the injection, the animals were tested for cue and contextual freezing, respectively. No significant differences were found among groups. (D) Rats were trained in FC and $48 \mathrm{~h}$ later were exposed to a novel context without any cue presentation and immediately after were injected with propranolol or saline i.p. Forty-eight hours and $96 \mathrm{~h}$ later, the animals were tested for cue and contextual freezing, respectively. No significant differences were found among groups.
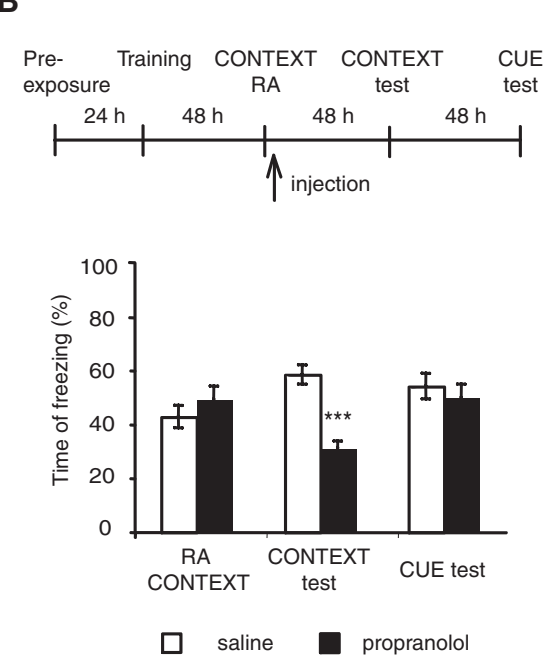

D
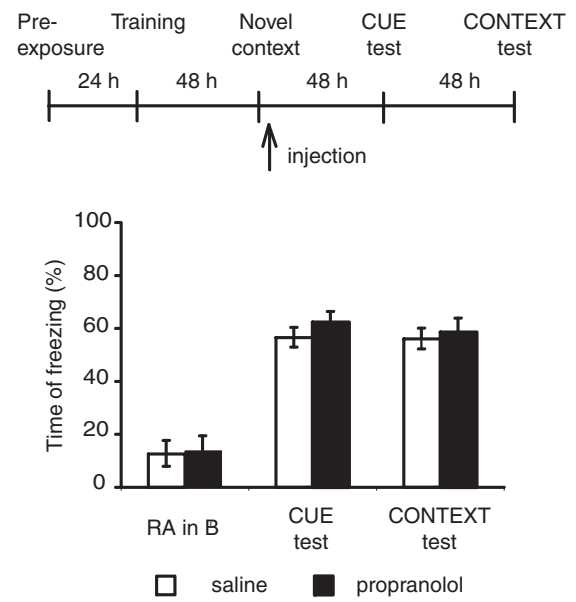

upon reactivation. In fact, when propranolol was injected $48 \mathrm{~h}$ after training in the absence of reactivation, no effect was found on either cued or contextual memories. A two-way ANOVA comparing freezing scores across treatment and test (cue and context tests) revealed no effect of treatment $\left(F_{(1,20)}=0.43, P=0.52\right)$, no effect of test $\left(F_{(1,20)}=0.00, P=0.97\right)$, and no treatment $\times$ test interaction $\left(F_{(1,20)}=\right.$ $0.14, P=0.72$ ). Bonferroni post-hoc test showed that rats from both treatment groups had no significant differences in freezing levels either in cue $(P>0.05)$ or context test $(P>0.05$; Fig. $2 \mathrm{C}$; Table 1$)$.

To test whether the disruption of contextual fear memory following cue reactivation and propranolol administration is due to context generalization, we tested whether the exposure to an unpaired context, that is, a context in which the animals never experienced a footshock, followed by propranolol administration, would affect contextual fear memory retention. As depicted in Figure $2 \mathrm{D}$ and Table 1, rats were trained in context A, and received propranolol after exposure to an unpaired context (context B) without any cue presentation. Two days later, they were tested for cued conditioning in context $\mathrm{B}$ and after two more days for contextual FC in context A. Two-way ANOVA comparing freezing scores across treatment and test (unpaired context, cue, and context tests) revealed no effect of treatment $\left(F_{(1,30)}=0.73, \quad P=0.4\right), \quad$ a significant effect of test $\left(F_{(2,30)}=65.95, \quad P<\right.$ $0.0001)$, and no test $\times$ treatment interaction $\left(F_{(2,30)}=0.14, P=0.87\right)$. Bonferroni ost-hoc test showed no significant difbetween treatment groups dur- novel context exposure $(P>$ in both cue $(P>0.05)$ and contextual memory $(P>0.05$; Fig. 2D).

In conclusion, propranolol disrupts both auditory and contextual memory reconsolidation if administered immediately after a cued reactivation. However, it selectively affects the contextual memory if administered immediately after a contextual reactivation.

\section{Propranolol disrupts freezing but not inhibitory avoidance memory}

revealed a significant effect of treatment $\left(F_{(1,28)}=14.95, P=\right.$ $0.0006)$, no effect of test $\left(F_{(1,28)}=3.14, P=0.09\right)$, and significant test $\times$ treatment interaction $\left(F_{(1,28)}=8.03, P<0.008\right)$. Bonferroni post-hoc test showed that compared with saline, the propranololtreated rats had a significant impairment in contextual fear memory $(P<0.001)$. On the other hand, no effect of propranolol was found $2 \mathrm{~d}$ later on auditory fear memory ( $P>0.05$; Fig. 2B).

The amnestic effect of propranolol in both groups of rats that underwent either cued or context reactivation was contingent
In the last set of experiments, we asked whether propranolol disrupts freezing, but not avoidance memory. We trained rats in IA, and during the training session presented them with a cue (the same tone used in FC) for the duration of the exposure to the lit compartment (14-54 sec). Two days later, rats were placed into the IA box for testing without the tone. This test reactivated the IA memory. Immediately after, they received an i.p. injection of propranolol. Two days later, the animals were tested for IA, and $2 \mathrm{~d}$ after this test they were tested for cue memory in a different 
A
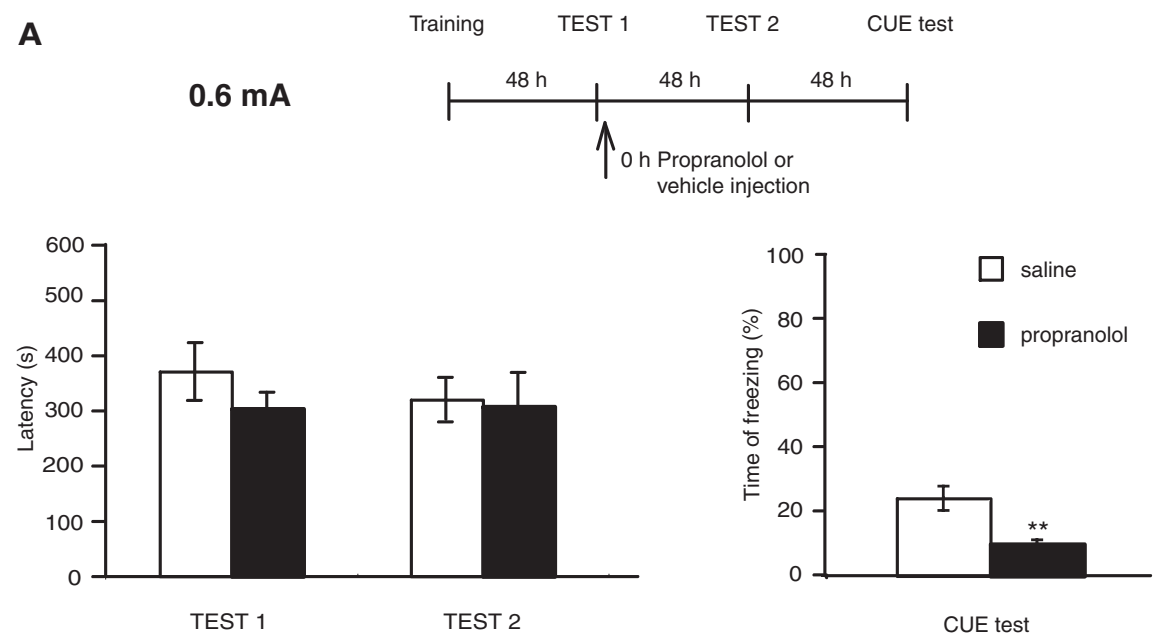

B
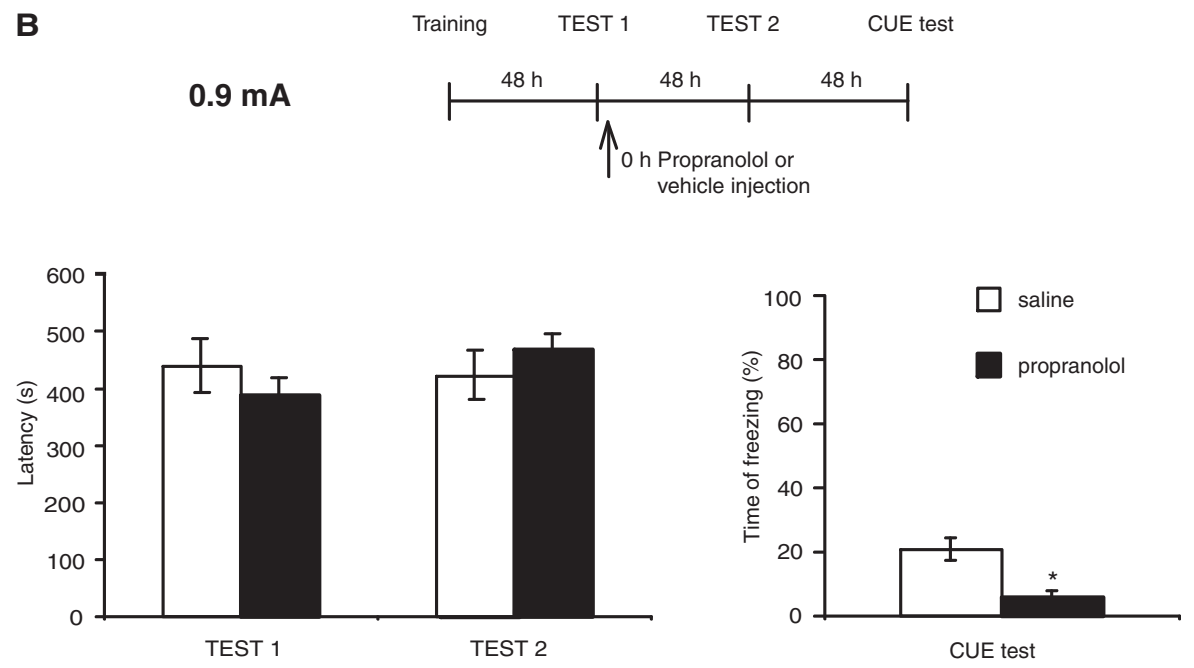

Figure 3. Propranolol disrupts freezing but not IA memory. Experimental timelines are shown above each experiment. Values of latencies are expressed in seconds and shown as means \pm SEM. Freezing scores are expressed as percent of the total time of testing and shown as means \pm SEM. $(A)$ Rats were trained in IA with $0.6 \mathrm{~mA}$ footshock intensity and, during training, presented with a tone. Forty-eight hours later, they were tested in IA, and immediately after, received an i.p. injection of propranolol or saline. Forty-eight hours and $96 \mathrm{~h}$ later, the animals were tested in IA and cue fear memory, respectively. Compared with saline, propranolol had no effect on IA retention, but significantly disrupted freezing (Student's $t$-test, $\left[{ }^{* *}\right] P<0.01$ ). (B) Rats underwent the same protocol as in $A$, except that a footshock of $0.9 \mathrm{~mA}$ was used during training. Compared with saline, propranolol had no effect on IA retention, but significantly disrupted freezing (Student's $t$-test, $\left[{ }^{*}\right] P<0.05$ ).

context (tone in context B). Two-way ANOVA comparing IA latencies to enter to the dark compartment across treatment and test revealed no effect of treatment $\left(F_{(1,26)}=0.13, P=0.72\right)$, no effect of test $\left(F_{(1,26)}=0.26 P=0.62\right)$, and no test $\times$ treatment interactions $\left(F_{(1,26)}=0.36 P=0.55\right)$. Bonferroni post-hoc test showed no significant differences between propranolol and saline-treated groups during IA Test $1(P>0.05)$, and IA Test 2 $(P>0.05)$. In contrast, although the freezing response was moderate, it was significantly reduced by propranolol (Student's $t$-test, $P<0.01$; Fig. 3A; Table 1).

To test whether a higher freezing level was elicited if the footshock intensity was increased, we repeated the experiment using $0.9 \mathrm{~mA}$ footshock. However, similar results were found (Fig. 3B; Table 1), indicating that the low freezing in the control group is not related to footshock intensity. Two-way ANOVA comparing
CUE test

IA latencies to enter into the dark compartment across treatment and test revealed no effect of treatment $\left(F_{(1,24)}=0.005, P=\right.$ $0.94)$, no effect of test $\left(F_{(1,24)}=0.15 P=\right.$ $0.7)$, and no test $\times$ treatment interactions $\left(F_{(1,26)}=1.94, P=0.18\right)$. Bonferroni posthoc test showed no significant differences between propranolol- and saline-treated groups during IA Test $1(P>0.05)$ and IA Test $2(P>0.05)$. In contrast, although the freezing response was moderate, it was significantly reduced by propranolol (Student's $t$-test $P<0.05$; Fig. 3B). Thus, in both experiments, compared with vehicle, propranolol significantly reduced freezing levels without affecting IA.

\section{Discussion}

Since propranolol might be important for potential clinical applications that target the reconsolidation of traumatic memories, this study aimed at investigating the effect of its systemic administration on the reconsolidation of different types of fear memories. Our results show that propranolol administered after retrieval does not affect the reconsolidation of IA, whereas as also shown by previous authors (Debiec and LeDoux 2004; Abrari et al. 2007), it disrupts the reconsolidation of auditory and contextual FC. We conclude that the efficacy of systemic administration of propranolol in disrupting the reconsolidation of fear memories is not general, but limited to some types of fear memories.

Furthermore, our data provide evidence that, in the classical conditioning paradigm, the effect of propranolol following retrieval by context exposure results in the selective disruption of contextual FC with no effect on cued conditioning; whereas propranolol administered after retrieval by the tone exposure results in the disruption of both.

The conclusion that propranolol fails to affect IA reconsolidation is based on our results showing no effect of treatment under several different conditions of shock intensity and propranolol administration modalities. First, post-retrieval propranolol administration always failed to affect the reconsolidation of IA induced by either $0.25,0.6$, and $0.9 \mathrm{~mA}$ footshock intensities. Second, pre-retrieval propranolol administration affected IA retrieval itself but not reconsolidation, as memory retention was intact at a subsequent test. Hence, in none of the conditions probed were we able to find an effect of propranolol on IA reconsolidation.

A previous study from Przybyslawski et al. (1999), who also used systemic administration of propranolol similar to that employed in our experiments $(10 \mathrm{mg} / \mathrm{kg}$, i.p. immediately after reactivation by testing), concluded that propranolol disrupts the reconsolidation of IA. Several reasons may account for the divergence between this study and ours. First, the authors used very different read-outs to express the avoidance response. The first was 
the latency to place two paws into the dark box, a parameter that is not commonly used in IA studies. It is unclear whether the rate of approach to the dark box with the two anterior paws represents a true avoidance response, because, during IA testing, the animals may approach the dark box but then avoid it. The second measure the authors reported to be sensitive to propranolol referred to a frequency distribution of a selected group of animals. In fact, they reported an effect on the latency to fully enter the dark box expressed as the frequency distribution of rats avoiding or not avoiding for $300 \mathrm{sec}$ among a selected group of rats that had perfect retention. Moreover, other dissimilarities exist between our protocol and that used by Przybyslawski et al. (1999), including the rat strain and the fact that, at the very weak $0.25 \mathrm{~mA}$ footshock intensity, our paradigm did not elicit a significant IA response compared to acquisition time. Nevertheless, with none of the shock intensities employed, from 0.25 to $0.9 \mathrm{~mA}$, we were able to find an effect of propranolol on memory reconsolidation.

Two questions that can be raised with regard to the lack of effect of propranolol in our studies are that we only investigated systemic administration and only used one dose, that is, $10 \mathrm{mg} /$ $\mathrm{kg}$. Whereas we cannot exclude that intracerebral administration of propranolol might affect IA reconsolidation, in the present study we chose to focus on systemic administrations, because our goal was to test for effects potentially relevant for clinical applications. Furthermore, the dose used in our studies is the same used in the majority of investigations that reported an effect of propranolol on memory consolidation and reconsolidation (e.g., Sara et al. 1995; Przybyslawski et al. 1999; Saber and Cain 2003; Debiec and LeDoux 2004; Diergaarde et al. 2006; Abrari et al. 2007; Milton et al. 2008; Rodriguez-Romaguera et al. 2009). A total of $10 \mathrm{mg} / \mathrm{kg}$ appears to be the highest dose that can be utilized systemically in rat without causing a toxic effect. In fact, in spontaneously breathing rats, propranolol administered at $30 \mathrm{mg} / \mathrm{kg}$ i.v. decreases heart rate and mean arterial blood pressure and causes hypoventilation, serious hypoxaemia, respiratory acidosis, and death by respiratory arrest (Toet et al. 1996).

Our data on the effect of propranolol on auditory FC confirm previous results obtained by Debiec and LeDoux (2004), who showed that propranolol administered either intra-amygdala or systemically after tone exposure disrupts auditory FC tested at a later time. This memory impairment was maintained over time and following the exposure to a reminder shock, suggesting that the effect of propranolol likely targets the reconsolidation and not the extinction of the memory. Similar results were shown with contextual FC by Abrari et al. (2007). Interestingly, we found that the reactivation by auditory tone exposure also affected the contextual trace, as propranolol administered after the reactivation by the tone in a different context also led to disruption of contextual fear memory. This result cannot be explained by context generalization and, therefore, reactivation of a generalized contextual trace for two reasons: First, the animals did not freeze in the context in which they were tested with tone before receiving the tone; and second, a reactivation by exposure to a different, unpaired context without tone did not lead to any memory disruption when the animals were tested for either cue or contextual FC. Thus, cue exposure must reactivate, at least in part, the conditioned context-specific trace in order for this to become labile and sensitive to the propranolol treatment. Given this outcome, we hypothesize that the hippocampus is, to some extent, critically implicated in tone memory, a conclusion in agreement with that of other authors (Maren 2008). In contrast, a reactivation by exposure to the same context in which the animals were trained, followed by propranolol administration, selectively disrupted the contextual memory and did not affect cued conditioning.
Why is FC, but not IA, affected by post-retrieval administration of propranolol? We speculate that propranolol may affect only some fear memory responses, like Pavlovian FC, but may spare more complex types of fear memory responses, such as those expressed by instrumental FC. Previous studies pointed out that several differences exist between the two FC paradigms. In Pavlovian FC the presentation of shock is independent of the animal's behavior, whereas in IA the animal must enter the dark chamber before being shocked. Thus, the involvement of different responses likely affects the neural substrates involved. Indeed, different circuits have been found to be critically recruited with the two types of learning (Wilensky et al. 2000; McGaugh 2004; Tinsley et al. 2004). In particular, the role of the amygdala in classical FC and IA has been shown to differ (for review, see Tinsley et al. 2004). In addition, data have been provided supporting the conclusion that in Pavlovian FC the amygdala is the site where plasticity underlying fear learning occurs, whereas in IA learning the role of the amygdala is to modulate the strength of an aversive memory that is stored elsewhere (Wilensky et al. 2000; McGaugh 2004) or, perhaps, in a more distributed fashion. If fundamental differences exist in the mechanisms underlying the consolidation mechanisms/circuits of the two memories (Wilensky et al. 2000; Kim and Jung 2006), it is not surprising that differences are also found during the reconsolidation process of the two memories (Alberini 2005; Alberini et al. 2006). Here, we propose that these differences include their sensitivity to propranolol.

In agreement with this interpretation are also our data showing that tone-evoked freezing following IA-tone conditioning is selectively affected by propranolol. Similar data were found when freezing was recorded during regular IA testing (data not shown). Although the freezing percent elicited with this paradigm was relatively modest, a significant disruption of freezing, but intact IA, was found with propranolol treatment. It is unclear why propranolol affects freezing following a contextual IA reactivation, whereas it does not affect cue-induced freezing in the Pavlovian FC paradigm following reactivation by context exposure. Possible explanations, as discussed above, likely invoke the differences between the two tasks and further experiments are needed to understand this point.

In conclusion, only some fear memories appear to be sensitive to the effect of propranolol, and these seem to be those involving a classical conditioning in which the amygdala acts as storage instead of a modulatory site, but not those that include more complex or distributed processing. This interpretation is in line with the results and conclusions of Vazdarjanova and McGaugh (1998), who reported that lesions of the amygdala complex block freezing, but only attenuate, and do not completely block a Y arm avoidance induced by shock. Our interpretation is also in agreement with the results reported by several other studies showing that propranolol significantly affects freezing (Debiec and LeDoux 2004; Abrari et al. 2007; Rodriguez-Romaguera et al. 2009) more than other fear responses, and particularly those involving more cognitive/explicit components (Selden et al. 1991; Parent et al. 1995; Vazdarjanova and McGaugh 1998; Walker et al. 2005).

Our results add to the controversial findings found with propranolol on memory reconsolidation. While the reconsolidation of potentiation of eyeblink conditioning, conditioning to natural or drug-associated reward, are disrupted by propranolol (Diergaarde et al. 2006; Milton et al. 2008; Kindt et al. 2009), the treatment has no effect on the reconsolidation of appetitive Pavlovian memory in rats (Lee and Everitt 2008) and on neutral and emotional words in humans (Tollenaar et al. 2008), or on a declarative measure for the acquired contingency between the CS and US (Kindt et al. 2009). It is possible that, as suggested 
by Kindt et al. (2009), propranolol targets the fear response and not the cognitive/explicit components of the fear response. However, because we did not test this aspect in our experiments, we cannot support this conclusion, and further studies are needed to understand this issue.

Our results indicate that the reconsolidation of complex fear memories, such as those based on instrumental conditioning, may not be sensitive to propranolol treatment. In conclusion, propranolol might not be, as expected, a general effective treatment for the disruption of all types of fear memory reconsolidation.

\section{Materials and Methods}

\section{Animals}

Long Evans adult male rats (Harlan) weighing between 250 and $350 \mathrm{~g}$ at the beginning of the experiments were used. Rats were housed on a 12-h light-dark cycle with ad libitum access to food and water. All experiments were conducted during the light cycle between 9 AM and 6 PM. All protocols complied with the National Institutes of Health Guide for the Care and Use of Laboratory Animals and were approved by the Mount Sinai School of Medicine Animal Care Committees.

\section{Inhibitory avoidance (IA)}

The IA was performed as previously described (Milekic et al. 2007). Briefly, the IA box (Model ENV-010MC, Med Associates) consisted of a lit (safe) compartment and a dark (shock) compartment separated by a door. In the dark compartment the rats received a footshock of either $0.25,0.6$, or $0.9 \mathrm{~mA}$ for $2 \mathrm{sec}$ via a constant current scrambler circuit delivered through the grid floor, as specified in each experiment. During the training sessions, rats were placed in the lit compartment facing away from the door. After $10 \mathrm{sec}$, the door leading to the dark chamber was opened. Once the animals fully entered the dark chamber (all four limbs contacting the grid in the dark chamber) the door was closed and, after a 2 -sec delay, a footshock was delivered for $2 \mathrm{sec}$. Ten seconds later, the rats were returned to their home cage. Forty-eight hours after training, the animals were tested (Test 1). This testing session also served as a reactivation session and was identical to the training sessions, except that no shock was delivered and the session was concluded after 540 sec. Latency to enter the dark compartment was recorded in seconds. Forty-eight hours after Test 1 the animals were tested again (Test 2).

\section{Fear conditioning (FC)}

Rats were conditioned and tested in FC in two different chambers, context $A$ and context $B$, respectively. Rats were trained in context A, a rectangular Plexiglass chamber $(30.5 \mathrm{~cm} \times 24.1 \mathrm{~cm} \times 21.0 \mathrm{~cm})$ with a metal grid floor (Model ENV-008 Med Associates). The chamber was washed with mint spray between training and testing of each animal. Context B was used only for reactivation or testing (Model ENV-515 Med Associates). Context B consisted of a square chamber $(43.2 \mathrm{~cm} \times 43.2 \mathrm{~cm} \times 43.2 \mathrm{~cm})$ with one transparent and three opaque Plexiglass walls and a Plexiglass flat floor that was washed with ylang-ylang spray between sessions. All rats were pre-exposed to both contexts (A and B) for $10 \mathrm{~min}$. On the next day, during training they were placed in context $\mathrm{A}$ for 120 sec and then presented with $30 \mathrm{sec}$ of the auditory cue (CS, consisting of a $5 \mathrm{kHz} 75 \mathrm{~dB}$ tone) paired with a 1.0-mA 1-sec footshock (US). Thirty seconds after the footshock they were removed and returned to their home cages. Forty-eight hours later, rats underwent a reactivation procedure that consisted of an exposure to either the cue or the context that they experienced during training (reminder), as detailed in the Results section. During the cue reactivation, the rats were placed in context $B$ for $120 \mathrm{sec}$ and then presented for $30 \mathrm{sec}$ with the same tone they experienced during the training. During the context reactivation, the rats were placed again into the training chamber (context A) for 90 sec. Freezing, which was defined as lack of movement except for breathing, was videotaped and scored during both reactivation and testing. All rats were tested in both cued and contextual tests, as specified in the Results section. During the cued test, animals were placed in context B and received four 30-sec cue presentations separated by a variable intertone interval $(120 \mathrm{sec}$ on average). An average of the four scores for each tone for each rat was used for the analysis. During the context test, animals were placed into context $\mathrm{A}$ and freezing was recorded and scored for $3 \mathrm{~min}$.

\section{IA and auditory FC}

IA was performed using the same protocols as described above. During training, the same sound used as an auditory cue during FC (CS, $5 \mathrm{kHz} 75 \mathrm{~dB}$ tone) was presented from the beginning of the session to the end of the footshock, thus lasting for 14-54 sec. Rats were tested for latency in the IA chamber without the tone $48 \mathrm{~h}$ later. This test served as a reactivation event (IA reactivation, Test 1 ). Two days later, the rats were tested again (Test 2) and latency to enter into the dark compartment was recorded. Finally, $48 \mathrm{~h}$ later, they were tested for cued conditioning in a different context (context B), as described in the fear-conditioning method.

\section{Pharmacological treatments}

Propranolol (Sigma-Aldrich) was dissolved in 0.9\% saline and injected intraperitoneally (i.p.) at $10 \mathrm{mg} / \mathrm{kg}$. This is among the highest doses used for behavioral effects (e.g., Debiec and LeDoux 2004; Abrari et al. 2007; Rodriguez-Romaguera et al. 2009). All treatments, including vehicles, were administered at $1 \mathrm{~mL} / \mathrm{kg}$.

\section{Statistical analysis}

Two-way ANOVA followed by Bonferroni-protected post-hoc test and Student's $t$-test were used as detailed in the Results section.

\section{Acknowledgements}

This work was funded by RO1MH074736 and NARSAD Independent Investigator Award to C.M.A. We thank Dillon Chen, Gabriella Pollonini, Akinobu Suzuki, Sarah Stern, and Dhananjay Bambah-Mukku for reading the manuscript and Reginald Miller and the Center for Comparative Medicine and Surgery facility at Mount Sinai School of Medicine for technical support.

\section{References}

Abrari K, Rashidy-Pour A, Semnanian S, Fathollahi Y. 2007. Administration of corticosterone after memory reactivation disrupts subsequent retrieval of a contextual conditioned fear memory: Dependence upon training intensity. Neurobiol Learn Mem 89: 178-184.

Alberini CM. 2005. Mechanisms of memory stabilization. Are consolidation and reconsolidation similar or distinct processes? Trends Neurosci 28: $51-56$.

Alberini CM, Milekic MH, Tronel S. 2006. Mechanisms of memory stabilization and de-stabilization. Cell Mol Life Sci 63: 999-1008.

Anokhin KV, Tiunova AA, Rose SP. 2002. Reminder effectsreconsolidation or retrieval deficit? Pharmacological dissection with protein synthesis inhibitors following reminder for a passive-avoidance task in young chicks. Eur J Neurosci 15: 1759-1765.

Brunet A, Orr SP, Tremblay J, Robertson K, Nader K, Pitman RK. 2008. Effect of post-retrieval propranolol on psychophysiologic responding during subsequent script-driven traumatic imagery in post-traumatic stress disorder. J Psychiatr Res 42: 503-506.

Davis HP, Squire LR. 1984. Protein synthesis and memory: A review. Psychol Bull 96: 518-559.

Debiec J, LeDoux JE. 2004. Disruption of reconsolidation but not consolidation of auditory fear conditioning by noradrenergic blockade in the amygdala. Neuroscience 129: 267-272.

Debiec J, LeDoux JE. 2006. Noradrenergic signaling in the amygdala contributes to the reconsolidation of fear memory: Treatment implications for PTSD. Ann N Y Acad Sci 1071: 521-524. 
Diergaarde L, Schoffelmeer AN, De Vries TJ. 2006. $\beta$-Adrenoceptor mediated inhibition of long-term reward-related memory reconsolidation. Behav Brain Res 170: 333-336.

Diergaarde L, Schoffelmeer AN, De Vries TJ. 2008. Pharmacological manipulation of memory reconsolidation: Towards a novel treatment of pathogenic memories. Eur J Pharmacol 585: 453-457.

Dudai Y. 2006. Reconsolidation: The advantage of being refocused. Curr Opin Neurobiol 16: 174-178.

Izquierdo I, Medina JH. 1997. Memory formation: The sequence of biochemical events in the hippocampus and its connection to activity in other brain structures. Neurobiol Learn Mem 68: 285-316.

Kandel ER. 2001. The molecular biology of memory storage: A dialogue between genes and synapses. Science 294: 1030-1038.

Kim JJ, Jung MW. 2006. Neural circuits and mechanisms involved in Pavlovian fear conditioning: A critical review. Neurosci Biobehav Rev 30: $188-202$.

Kindt M, Soeter M, Vervliet B. 2009. Beyond extinction: Erasing human fear responses and preventing the return of fear. Nat Neurosci 12: 256-258.

Lee JL, Everitt BJ. 2008. Reactivation-dependent amnesia in Pavlovian approach and instrumental transfer. Learn Mem 5: 597-602.

Maren S. 2008. Pavlovian fear conditioning as a behavioral assay for hippocampus and amygdala function: Cautions and caveats. Eur J Neurosci 28: 1661-1666.

McGaugh JL. 2000. Memory-a century of consolidation. Science 287: $248-251$.

McGaugh JL. 2004. The amygdala modulates the consolidation of memories of emotionally arousing experiences. Апnи Rev Neurosci 27: $1-28$.

Milekic MH, Alberini CM. 2002. Temporally graded requirement for protein synthesis following memory reactivation. Neuron 36: $521-525$.

Milekic MH, Pollonini G, Alberini CM. 2007. Temporal requirement of C/ EBP $\beta$ in the amygdala following reactivation but not acquisition of inhibitory avoidance. Learn Mem 14: 504-511.

Milton AL, Lee JL, Everitt BJ. 2008. Reconsolidation of appetitive memories for both natural and drug reinforcement is dependent on $\beta$-adrenergic receptors. Learn Mem 15: 88-92.

Nader K, Schafe GE, LeDoux JE. 2000. The labile nature of consolidation theory. Nat Rev Neurosci 1: 216-219.

Parent MB, Quirarte GL, Cahill L, McGaugh JL. 1995. Spared retention of inhibitory avoidance learning after post-training amygdala lesions. Behav Neurosci 109: 803-807.

Przybyslawski J, Roullet P, Sara SJ. 1999. Attenuation of emotional and nonemotional memories after their reactivation: Role of $\beta$ adrenergic receptors. J Neurosci 19: 6623-6628.

Rodriguez-Romaguera J, Sotres-Bayon F, Mueller D, Quirk GJ. 2009. Systemic propranolol acts centrally to reduce conditioned fear in rats without impairing extinction. Biol Psychiatry 65: 887-892.

Saber AJ, Cain DP. 2003. Combined $\beta$-adrenergic and cholinergic antagonism produces behavioral and cognitive impairments in the water maze: Implications for Alzheimer disease and pharmacotherapy with $\beta$-adrenergic antagonists. Neuropsychopharmacology 28: $1247-1256$.

Sara SJ. 2000. Retrieval and reconsolidation: Toward a neurobiology of remembering. Learn Mem 7: 73-84.

Sara SJ, Dyon-Laurent C, Herd A. 1995. Novelty seeking behavior in the rat is dependent upon the integrity of the noradrenergic system. Brain Res Cog Brain Res 2: 181-187.

Selden NR, Everitt BJ, Jarrard LE, Robbins TW. 1991. Complementary roles for the amygdala and hippocampus in aversive conditioning to explicit and contextual cues. Neuroscience 42: 335-350.

Taubenfeld SM, Riceberg JS, New AS, Alberini CM. 2008. Preclinical assessment for selectively disrupting a traumatic memory via postretrieval inhibition of glucocorticoid receptors. Biol Psychiatry 65: 249-257.

Taylor JR, Olausson P, Quinn JJ, Torregrossa MM. 2009. Targeting extinction and reconsolidation mechanisms to combat the impact of drug cues on addiction. Neuropharmacology 1: 186-195.

Tinsley MR, Quinn JJ, Fanselow MS. 2004. The role of muscarinic and nicotinic cholinergic neurotransmission in aversive conditioning: Comparing Pavlovian fear conditioning and inhibitory avoidance. Learn Mem 11: 35-42.

Toet AE, van de Kuil A, Vleeming W, Wemer J, Bode W, Meulenbelt J, de Wildt DJ. 1996. Toxic doses of rac-, $(-)-(\mathrm{S})$ - and (+)-(R)-propranolol in rats and rabbits. Chirality 8: 411-417.

Tollenaar MS, Elzinga BM, Spinhoven P, Everaerd W. 2008. Immediate and prolonged effects of cortisol, but not propranolol, on memory retrieval in healthy young men. Neurobiol Learn Mem 91: $23-31$.

Tollenaar MS, Elzinga BM, Spinhoven P, Everaerd W. 2009. Psychophysiological responding to emotional memories in healthy young men after cortisol and propranolol administration. Psychopharmacology (Berl) 203: 793-803.

Tronel S, Alberini CM. 2007. Persistent disruption of a traumatic memory by postretrieval inactivation of glucocorticoid receptors in the amygdala. Biol Psychiatry 62: 33-39.

Vazdarjanova A, McGaugh JL. 1998. Basolateral amygdala is not critical for cognitive memory of contextual fear conditioning. Proc Natl Acad Sci 95: $15003-15007$.

Walker DL, Paschall GY, Davis M. 2005. Glutamate receptor antagonist infusions into the basolateral and medial amygdala reveal differential contributions to olfactory vs. context fear conditioning and expression. Learn Mem 2: 120-129.

Wilensky AE, Schafe GE, LeDoux JE. 2000. The amygdala modulates memory consolidation of fear-motivated inhibitory avoidance learning but not classical fear conditioning. J Neurosci 20: 7059-7066.

Received March 04, 2010; accepted in revised form April 20, 2010. 


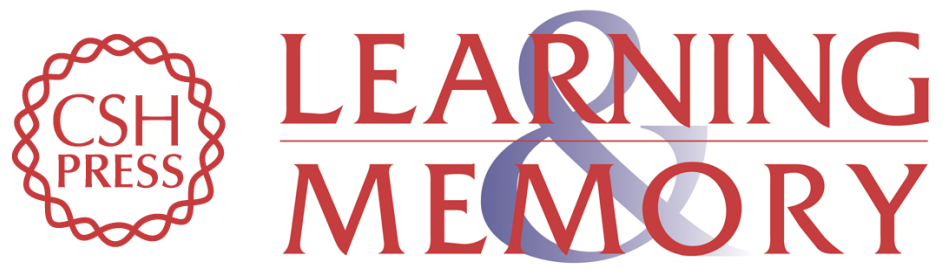

\section{Limited efficacy of propranolol on the reconsolidation of fear memories}

Elizaveta V. Muravieva and Cristina M. Alberini

Learn. Mem. 2010, 17:

Access the most recent version at doi:10.1101//m.1794710

References This article cites 40 articles, 9 of which can be accessed free at:

http://learnmem.cshlp.org/content/17/6/306.full.html\#ref-list-1

License

Email Alerting Receive free email alerts when new articles cite this article - sign up in the box at the Service top right corner of the article or click here. 